\title{
In vitro maturation, fertilization and development of follicular oocytes from buffalo (Bubalus bubalis)
}

\author{
S. M. Totey, G. Singh, M. Taneja, C. H. Pawshe and G. P. Talwar \\ Embryo Biotechnology Laboratory, National Institute of Immunology, Shahid Jeet Singh Marg, \\ New Delhi-110067, India
}

\begin{abstract}
Summary. Cumulus-oocyte complexes, 5596, were cultured for $24 \mathrm{~h}$ in either TCM-199 or Ham's F-10 with or without gonadotrophins and supplemented with either $20 \%$ buffalo oestrous serum (BES) or fetal calf serum (FCS). The maturation rates of oocytes cultured in TCM-199 or Ham's F-10 medium supplemented with $20 \%$ BES were $47.4 \pm 17.8$ and $44 \cdot 8 \pm 25 \cdot 6$, respectively. Addition of luteinizing hormone $(\mathrm{LH})\left(5 \mu \mathrm{g} \mathrm{ml}^{-1}\right)$ significantly improved the maturation rate in the Ham's F-10 medium supplemented with $20 \%$ BES $(76.8 \pm 18.3)$, but follicle-stimulating hormone (FSH) $\left(0.5 \mu \mathrm{g} \mathrm{ml}^{-1}\right)$ and oestradiol $\left(1 \mu \mathrm{g} \mathrm{ml}^{-1}\right)$ failed to synergize with $\mathrm{LH}(71 \cdot 7 \pm 19 \cdot 5)$. In the TCM-199 system, LH failed to enhance the maturation rate but the addition of FSH and oestradiol significantly enhanced the proportion of mature oocytes $(42.7 \pm 1.4$ and $81.7 \pm 14.5$, respectively; $P<0.05$ ). Frozen-thawed spermatozoa prepared in Bracket and Oliphant (BO) medium and treated with $5 \mathrm{mmol}$ caffeine $\mathrm{l}^{-1}+10 \mu \mathrm{g}$ heparin showed a higher fertilization rate $(29.8 \%)$ than those treated in Hepes-Talp and treated with $10 \mu \mathrm{g}$ heparin $\mathrm{ml}^{-1}(19 \cdot 6 \%)$. Fertilization rate was significantly improved when fresh ejaculated spermatozoa treated with $5 \mathrm{mmol}$ caffeine $1^{-1}$ and $10 \mu \mathrm{g}$ heparin in $\mathrm{BO}$ medium $(50 \%)$ was used. Rate of cleavage and development were also higher when in vitro fertilization was carried out with fresh ejaculated spermatozoa treated with caffeine and heparin $(34 \cdot 1$ and $36.8 \%$, respectively) than with frozen-thawed spermatozoa ( 27.0 and $22.0 \%$, respectively).

Development rate was enhanced when fertilized ova were cultured in ligated rabbit oviduct $(28.0 \%)$ than when co-cultured on oviductal cell monolayers $(8 \cdot 2 \%)$. The results indicate that oocytes cultured in medium supplemented with BES and gonadotrophins reveal high rates of maturation and development to the blastocyst stage after fertilization with fresh ejaculated spermatozoa.
\end{abstract}

Kerwords: oocytes; maturation; fertilization; culture; buffalo

\section{Introduction}

The lower reproductive capacity of domestic buffalo than of cattle is a major impediment to using buffalo for milk and meat production worldwide. This is particularly relevant in Asia, where $95 \%$ of the world population of domestic buffaloes is found. Buffalo is the mainstay of the Indian dairy industry; $55 \%$ of the milk production is contributed by 19 million buffaloes. Several international organizations have emphasized the potential of buffaloes in the agricultural economy of many developing nations in Asia, but domestic buffalo continues to be neglected despite its superiority over cattle under the harsh environments of the tropics.

Recent advances in embryo transfer technology have allowed progress towards increasing the number of offspring produced from genetically superior buffaloes. The application of bovine embryo transfer technology to buffalo has had only a limited success (Vlahov et al., 1985; Kurup, 1988; Karaivanov et al., 1990; Madan, 1990). However, there is slow, yet steady, progress in terms of superovulatory response and embryo recovery (Mishra et al., 1991). 
In vitro fertilization may prove useful for obtaining large numbers of embryos for transfer. The first ruminant offspring from in vitro fertilization was a bull calf born in 1981 (Bracket et al., 1982). Since then, fertilization has been accomplished in vitro in many species. Little information is available on in vitro maturation and fertilization of buffalo oocytes (Majumdar et al., 1988; Singh et al., 1989; Totey et al., 1991). The low reproductive capacity of buffalo, for example in terms of total number of follicles in the ovary, high percentage of atretic follicles, changes in acrosomal proteins and membrane damage during freezing, is a major problem. Surti buffaloes have 12000 primordial follicles and Nilli Ravi have 19000 primordial follicles in contrast to hundred thousands in cattle (Samad \& Nasseri, 1979). This study was conducted as part of a long-term investigation of in vitro fertilization mechanisms in buffalo. We investigated a suitable protocol for in vitro maturation (IVM) and in vitro fertilization (IVF) of buffalo oocytes and determined the developmental competence of these embryos in vitro and in vivo.

\section{Materials and Methods}

\section{Collection of ovaries}

Ovaries from sexually mature buffalo, which were probably well past their reproductive prime, were obtained at a local slaughterhouse within $2-3 \mathrm{~h}$ of slaughter and transported to the laboratory at $25-30^{\circ} \mathrm{C}$ in normal saline supplemented with $50 \mu \mathrm{g}$ gentamycin $\mathrm{ml}^{-1}$. Ovaries were washed four times in fresh phosphate-buffered saline supplemented with $50 \mu \mathrm{g}$ gentamycin $\mathrm{ml}^{-1}$. Precautions were taken to minimize bacterial contamination by conducting procedures in highly sterile conditions.

\section{Oocyte recovery}

Small antral follicles (2-6 mm diameter) were aspirated into $10 \mathrm{ml}$ disposable syringes fitted with 18 -gauge needles. The follicular fluid aspirates were pooled in a sterile $50 \mathrm{ml}$ centrifuge tube and held for an additional 30 min. Cumulusoocyte complexes, 5596, were isolated under a low-power magnification zoom stereo microscope (SMZ-2, Nikon, Japan) and washed five times in Tyrode's lactate medium buffered with $25 \mathrm{mmol}$ Hepes $1^{-1}$ and supplemented with $3 \mathrm{mg} \mathrm{BSA}$, fraction $\mathrm{V} \mathrm{ml}^{-1}$ and $0.25 \mathrm{mmol}$ sodium pyruvate $\mathrm{l}^{-1}$. Only oocytes enclosed with compact cumulus cells were used for maturation. Aseptic precautions were taken during these procedures. Number of usable oocytes varied from 20 to 60 per 100 ovaries. Owing to a low recovery rate, each treatment was studied individually. Experiments were performed between November and January (1987-1990).

\section{Oocyte maturation}

Cumulus-oocyte complexes were assigned to one of the following eight treatment groups and cultured for $24 \mathrm{~h}$ (ten oocytes in $50 \mu \mathrm{l}$ droplets) under sterile paraffin oil at $39^{\circ} \mathrm{C}$ and a moist atmosphere of $5 \% \mathrm{CO}_{2}$ in air.

(1) Ham's F-10 medium plus $10 \%$ fetal calf serum (FCS), $0.5 \mu \mathrm{g} \mathrm{oFSH} \mathrm{ml}{ }^{-1}$ (NIDDK, NHPP) and $5 \mu \mathrm{g} \mathrm{oLH} \mathrm{ml^{-1 }}$ (NIDDK, NHPP) $+1 \mu \mathrm{g}$ oestradiol $\mathrm{ml}^{-1}$ (Sigma Chemical Co.);

(2) Ham`s F-10 medium plus $20 \%$ BES (prepared from blood taken during oestrus and heat-inactivated at $56^{\circ} \mathrm{C}$ for $30 \mathrm{~min}$ );

(3) Ham's F-10 medium plus $20 \% \mathrm{BES}, 5 \mu \mathrm{g} \mathrm{oLH} \mathrm{ml}^{-1}$ and $1 \mu \mathrm{g}$ oestradiol $\mathrm{ml}^{-1}$;

(4) Ham's F-10 medium plus $20 \%$ BES, $0.5 \mu \mathrm{g} \mathrm{oFSH} \mathrm{ml} l^{-1}, 5 \mu \mathrm{g} \mathrm{oLH} \mathrm{ml} l^{-1}$ and $1 \mu \mathrm{g}$ oestradiol ml $\mathrm{ml}^{-1}$;

(5) TCM-199 plus $10 \% \mathrm{FCS}, 0.5 \mu \mathrm{g}$ oFSH ml $\mathrm{m}^{-1}, 5 \mu \mathrm{g} \mathrm{oLH} \mathrm{ml} l^{-1}$ and $1 \mu \mathrm{g}$ oestradiol ml ${ }^{-1}$;

(6) TCM-199 plus $20 \%$ BES;

(7) TCM-199 plus $20 \%$ BES, $5 \mu \mathrm{g} \mathrm{oLH} \mathrm{ml}{ }^{-1}$ and $1 \mu \mathrm{g}$ oestradiol $\mathrm{ml}^{-1}$;

(8) TCM-199 plus 20\% BES, $0.5 \mu \mathrm{g} \mathrm{oFSH} \mathrm{ml} l^{-1}, 5 \mu \mathrm{g} \mathrm{oLH} \mathrm{ml} l^{-1}$ and $1 \mu \mathrm{g}$ oestradiol $\mathrm{ml}^{-1}$.

Maturation percentage was assessed after $24 \mathrm{~h}$ in culture by fixing 2697 oocytes in acetic acid:ethanol (1:3) and staining with $1 \%$ orcein in $45 \%$ acetic acid. Stage of meiosis was determined under a phase contrast microscope (Microphot: FXA, Nikon, Japan). The remaining oocytes were scored by cumulus mass expansion and secretion of first polar body and subjected to fertilization.

\section{Sperm preparation and IVF}

Fresh ejaculate or frozen thawed spermatozoa were used for in vitro insemination by two methods. In the first method (Parrish et al., 1986) fresh ejaculate or frozen-thawed semen (three to four $0.5-\mathrm{ml}$ straws of buffalo frozen 
semen thawed in water at $35-37^{\circ} \mathrm{C}$ for $1 \mathrm{~min}$ ) was washed twice in Hepes-Talp medium supplemented with $6 \mathrm{mg}$ BSA $\mathrm{ml}^{-1}$ essentially free of fatty acids (Sigma Chemical Co.) and I mmol sodium pyruvate $1^{-1}$ ( $\mathrm{pH} 7 \cdot 4$ ) by centrifugation at $833 \mathrm{~g}$ for $10 \mathrm{~min}$ each. A sperm pellet was then carefully layered under $1 \mathrm{ml}$ Hepes-Talp for swim up; $1 \mathrm{~h}$ later the top $0.8 \mathrm{ml}$ of medium was removed and centrifuged again for $10 \mathrm{~min}$. The sperm pellet was resuspended to $200 \mu \mathrm{l}$ of Hepes-Talp. Sperm motility and concentration were assessed with a haemocytometer. The medium for fertilization was a modified Tyrode's medium ( $\mathrm{pH} 7 \cdot 4)$. Droplets $(48 \mu \mathrm{l})$ were prepared under sterile paraffin oil and equilibrated with $5 \% \mathrm{CO}_{2}$ in air for at least $2 \mathrm{~h}$ before use. A $2-\mu \mathrm{l}$ aliquot of sperm suspension was added (to a final concentration of $1 \times 10^{6}$ spermatozoa $\mathrm{ml}^{-1}$ ) to droplets of fertilization medium containing 5-10 oocytes, $10 \mu \mathrm{g}$ intestinal mucosal heparin $\mathrm{ml}^{-1}$ (176 USP units $\mathrm{ml}^{-1}$, Sigma Chemical Co.) or $10 \mu \mathrm{mol}$ penicillamine $\mathrm{l}^{-1}$ plus $2 \mu$ mol sodium metabisulfite $1^{-1}, I \mu \mathrm{mol}$ hypotaurine $1^{-1}$ and $20 \mu \mathrm{mol}$ adrenaline $1^{-1}$ or heparin plus $10 \mu \mathrm{mol}$ penicillamine $1^{-1}, 2 \mu \mathrm{mol}$ sodium metabisulfite $1^{-1}, 1 \mu \mathrm{mol}$ hypotaurine $1^{-1}$ and $20 \mu \mathrm{mol}$ adrenaline $1^{-1}$.

In the second method (Niwa \& Ohgoda, 1988) fresh ejaculated or frozen-thawed semen were washed twice in BO medium (Bracket \& Oliphant, 1975) containing $10 \mathrm{mmol}$ caffeine $\mathrm{l}^{-1}$ without BSA. The sperm pellet was resuspended in $\mathrm{BO}$ medium as used for washing to give a $2 \times 10^{6}$ spermatozoa $\mathrm{ml}^{-1}$. Matured oocytes were washed twice with $\mathrm{BO}$ medium and placed into $50-\mu 1$ droplets of BO medium supplemented with $20 \mathrm{mg}$ BSA (essentially free of fatty acids), $20 \mu \mathrm{g}$ heparin and covered with sterile paraffin oil and equilibrated with $5 \% \mathrm{CO}_{2}$ in air for at least $2 \mathrm{~h}$ before use. The sperm suspension $\left(50 \mu \mathrm{l}\right.$ aliquot) was introduced into $50 \mu \mathrm{l}$ of the medium which gave a final concentration of $1 \times 10^{6}$

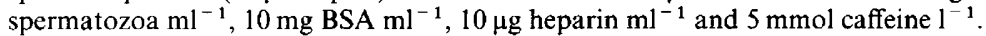

Spermatozoa and oocytes were incubated for $22-24 \mathrm{~h}$ in a $\mathrm{CO}_{2}$ incubator at $39^{\circ} \mathrm{C}$ and oocytes were then washed, mounted, fixed and stained with orcein for examination of sperm penetration and two pronuclei.

\section{Embryo culture}

After $22 \mathrm{~h}$ co-incubation of sperms and eggs, ova were removed from fertilization droplets, stripped of cumulus cells by repeated pipetting through a small-bore pipette and assigned randomly either to culture in ligated rabbit oviduct or to co-culture with 7 day-old oviductal cell monolayer in TCM-199 supplemented with $10 \%$ FCS and $50 \mu \mathrm{l}$ gentamycin $\mathrm{ml}^{-1}$. The embryos were examined under the microscope every $24 \mathrm{~h}$.

\section{Data analysis}

Oocyte maturation was indicated in the fresh state by cumulus expansion, the presence of a polar body and metaphase II plate. The maturation rate was recorded as the total number of oocytes that matured over the total number of oocytes cultured. Fertilization rate was assessed by observing male and female pronuclei and cleavage rate by two-cell and four-cell stage. Development of cleaved eggs to blastocysts and morula was observed on day 5-6.

Statistical analyses were made by $\chi^{2}$ test.

\section{Results}

Overall yield of the oocytes recovered by aspiration of buffalo ovaries was quite low compared with that in cattle. The maximum number of usable oocytes recovered per ovary using follicles of 2$6 \mathrm{~mm}$ diameter was $0 \cdot 4$. Average number of total oocytes per ovary was $0 \cdot 7.40 \cdot 8 \%$ of the oocytes $(0 \cdot 3$ per ovary) were atretic (Table 1$)$.

Table 1. Oocytes recovered by aspiration for buffalo in vitro fertilization

\begin{tabular}{lcc}
\hline & Total & Per ovary \\
\hline Number of ovaries & 12263 & - \\
Oocytes & 8995 & 0.73 \\
Nonatretic (usable) & $5323(59 \cdot 0 \%)$ & 0.43 \\
Atretic & $3672(41.0 \%)$ & 0.31 \\
\hline
\end{tabular}

The medium supplemented with $20 \% \mathrm{BES}$ and gonadotrophins resulted in marked expansion of cumulus cells characteristic of matured ova (Figs 1 and 2). Maturation rate was significantly higher $(P<0.05)$ in both media when $20 \%$ BES was added with LH, FSH and oestradiol than in media supplemented with $20 \%$ BES alone (Table 2). Addition of $5 \mu \mathrm{g} \mathrm{ml}^{-1} \mathrm{LH}$ in Ham's 


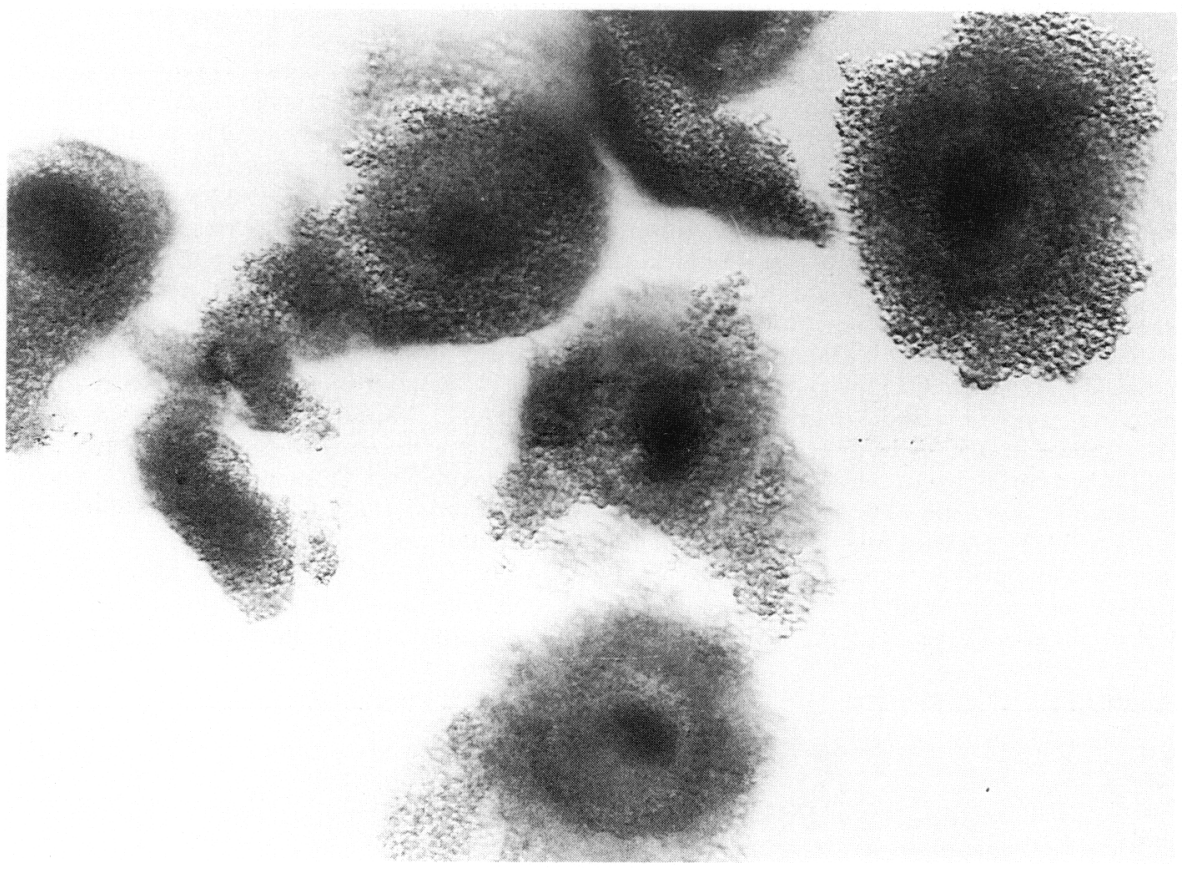

Fig. 1. Immature buffalo oocytes $(\times 85)$.

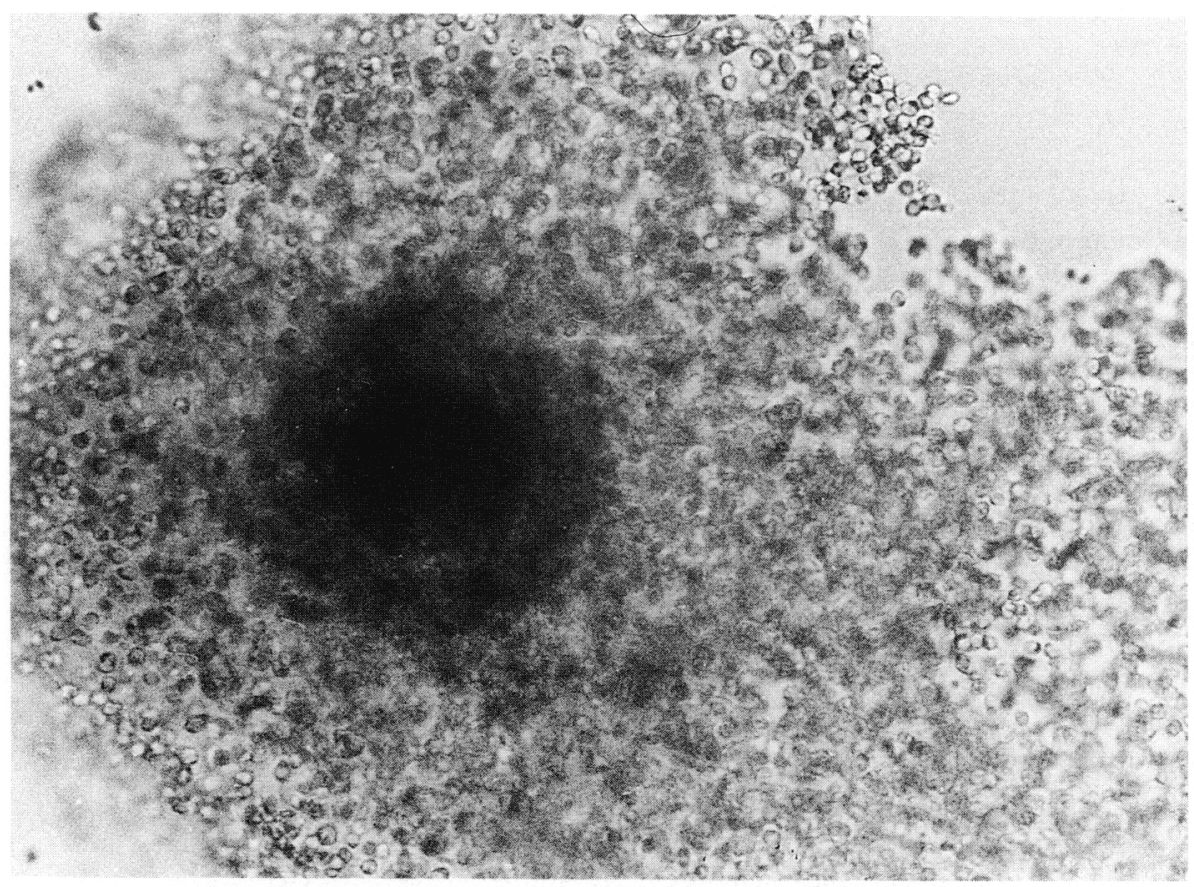

Fig. 2. Buffalo oocyte after maturation: expansion of cumulus cells is visible $(\times 85)$. 
Table 2. Influence of serum and gonadotrophins on in vitro maturation of buffalo oocytes

\begin{tabular}{lcccc}
\hline Medium & Serum & Hormones & $\begin{array}{c}\text { Total } \\
\text { oocytes }\end{array}$ & $\begin{array}{c}\text { Maturation \% } \\
\text { mean } \pm \text { SD }\end{array}$ \\
\hline Hams F-10 & FCS & oFSH + oLH + oestradiol & 967 & $69 \cdot 2 \pm 18 \cdot 4^{* *}$ \\
& BES & oL & 401 & $44 \cdot 8 \pm 25 \cdot 6^{*}$ \\
& BES & oLH & 954 & $76 \cdot 8 \pm 18 \cdot 3^{* *}$ \\
TC-199 & BES & oFSH + oLH + oestradiol & 1736 & $71 \cdot 7 \pm 19 \cdot 5^{* *}$ \\
& FCS & oFSH + oLH + oestradiol & 1043 & $63 \cdot 6 \pm 16 \cdot 19$ \\
& BES & & 188 & $47 \cdot 4 \pm 17 \cdot 8^{*}$ \\
& BES & oLH - & 140 & $42 \cdot 7 \pm 1 \cdot 4$ \\
& BES & oLH + oFSH + oestradiol & 167 & $81 \cdot 7 \pm 14 \cdot 5^{* *}$ \\
\hline
\end{tabular}

$*<* * P<0.05$.

FCS: fetal calf serum; BES: buffalo oestrous serum; oFSH: ovine follicle stimulating hormone; oLH: ovine luteinizing hormone.

Table 3. Fertilization and cleavage rate using frozen-thawed and fresh ejaculated semen for buffalo in vitro fertilization

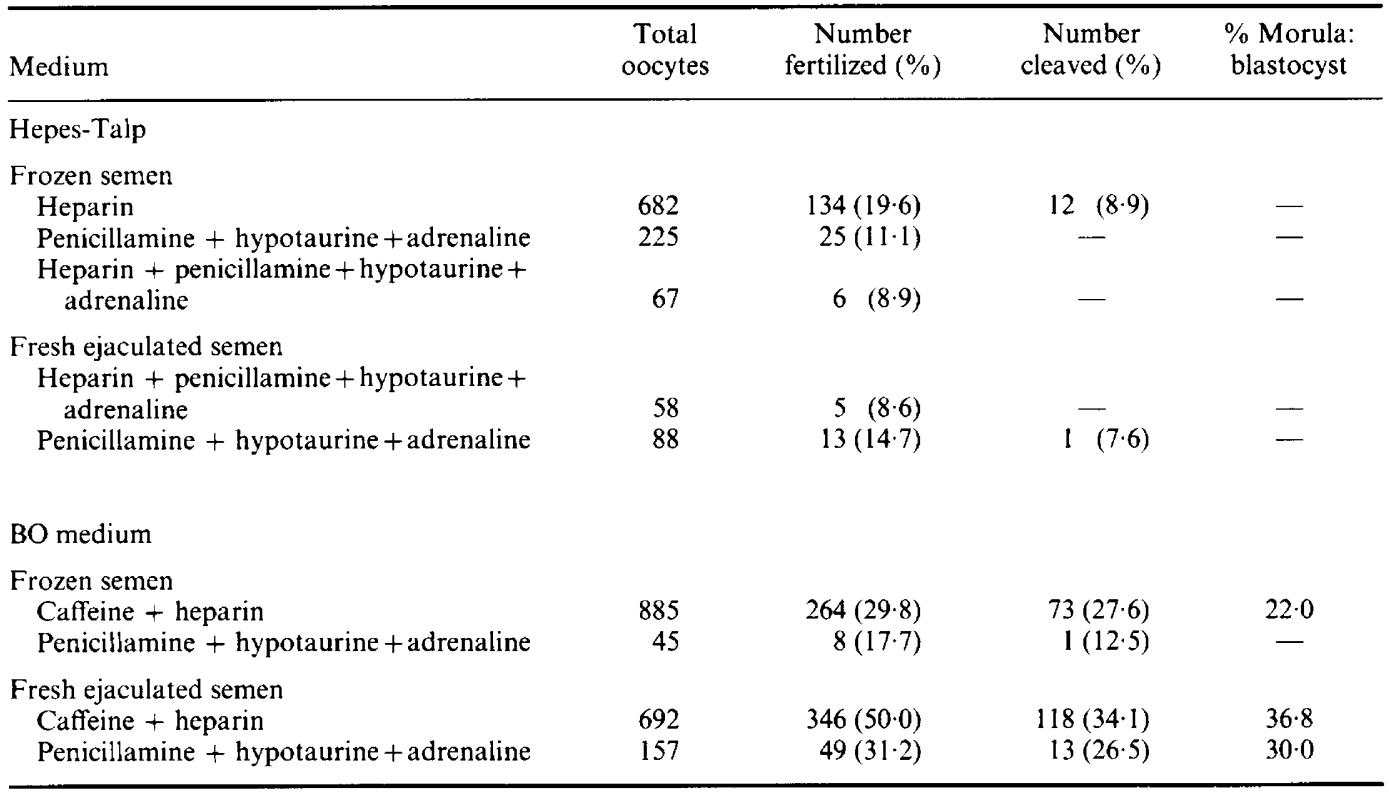

F-10 medium supplemented with $20 \%$ BES enhanced the maturation rate but addition of FSH or oestradiol failed to synergize with LH in Ham's F-10 medium. However, addition of $5 \mu \mathrm{g} \mathrm{LH} \mathrm{ml}^{-1}$ in TCM-199 failed to enhance the rate of maturation, but FSH and oestradiol did so significantly $(P<0.05)$.

A low fertilization rate $(19.6 \%)$ was achieved with frozen semen capacitated with $10 \mu \mathrm{g}$ heparin $\mathrm{ml}^{-1}$ in Hepes-Talp medium. This rate was not significantly increased by stimulating sperm motility with penicillamine + hypotaurine + adrenaline either alone or in combination with heparin (11.1 and 8.95\%, respectively). In addition fertilization rate did not improve when fresh ejaculated semen was used in Hepes-Talp; it was significantly enhanced when frozen semen was capacitated with $5 \mathrm{mmol}$ caffeine $\mathrm{l}^{-1}$ plus $10 \mu \mathrm{g}$ heparin $\mathrm{ml}^{-1}$ in BO medium $(29.8 \% ; P<0.05)$, and further increased when fresh ejaculated spermatozoa were capacitated in the same manner $(50.0 \% ; P<0.05)$ (Table 3 and Fig. 3). 


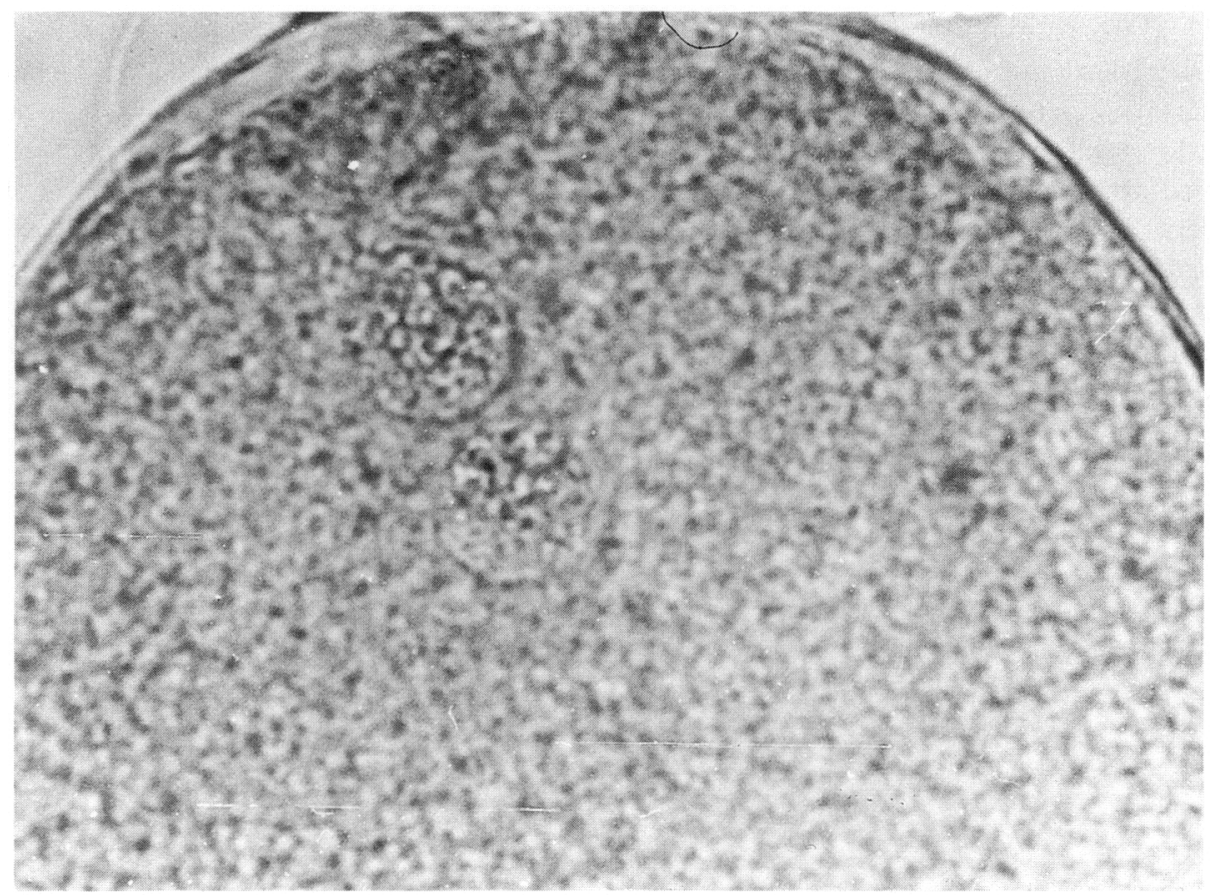

Fig. 3. Fertilized buffalo ovum, showing male and female pronucleus $(\times 250)$.

Table 4. Fertilization rate using freshly ejaculated, frozen and diluted semen stored at $4^{\circ} \mathrm{C}$ for $24 \mathrm{~h}$ of buffalo bull no. PR 54

\begin{tabular}{lccc}
\hline Semen & $\begin{array}{c}\text { Number of oocytes } \\
\text { inseminated }\end{array}$ & $\begin{array}{c}\text { Oocytes } \\
\text { fertilized }\end{array}$ & $\begin{array}{c}\text { Fertilization } \\
\%\end{array}$ \\
\hline Fresh & 35 & 27 & $77 \cdot 1^{*}$ \\
Diluted and stored & 20 & 7 & $35 \cdot 0^{* * a}$ \\
at $4{ }^{\circ} \mathrm{C}$ for $24 \mathrm{~h}$ & 30 & 7 & $23 \cdot 3^{* * b}$ \\
Frozen & &
\end{tabular}

${ }^{*}<{ }^{* *} P<0.05 ;{ }^{\mathrm{a}}<{ }^{\mathrm{b}} P<0.05$.

The rate of cleavage was low $(8.9 \%)$ after insemination with frozen-thawed semen treated with $10 \mu \mathrm{g}$ heparin $\mathrm{ml}^{-1}$ in Hepes-Talp. However, cleavage rate was significantly $(P<0 \cdot 05)$ increased to $27.6 \%$ when frozen-thawed spermatozoa were capacitated with caffeine plus heparin in BO medium and further increased to $34.1 \%$ with fresh ejaculated semen treated with caffeine plus heparin in BO medium. Similarly, development of embryos to morula and blastocyst was also increased from $0 \%$ to $22.0 \%$ and $36.8 \%$ when frozen and fresh ejaculated semen was capacitated in caffeine and heparin, respectively (Table 3 ). Fertilization rate was $17.7 \%$ when frozen-thawed spermatozoa treated with penicillamine and hypotaurine and adrenaline were used. Fertilization rate was increased significantly $(P<0.05)$ to $31.2 \%$ when fresh ejaculated semen was used. Cleavage rate was also significantly increased from $12 \cdot 5 \%$ (frozen-thawed spermatozoa) to $26.5 \%$ (fresh ejaculated spermatozoa).

Fresh ejaculated semen, diluted semen stored at $4^{\circ} \mathrm{C}$ and frozen semen of one particular bull (PR 54) from the same collection for buffalo IVF were used to confirm the low fertilization rate with frozen semen. A high fertilization rate $(77 \cdot 1 \%)$ was observed when fresh ejaculated semen was used, whereas fertilization rate was reduced significantly to $35.0 \%$ and $23 \cdot 3 \%(P<0.05)$ when 
diluted and frozen-thawed semen was used, respectively. These results confirmed that preservation and freezing of buffalo semen reduces the fertilization capacity of spermatozoa significantly (Table 4).

Buffalo oviductal cells in monolayer culture did not improve the proportion of embryos cleaving past the four-cell stage. Since most of the embryos did not go beyond the four-cell stage, it is yet to be confirmed whether a classical block at the four-cell stage occurs in in vitro fertilized buffalo embryos. However, there was a significant improvement when embryos were co-cultured in ligated rabbit oviduct ( $11 \%$ versus $38 \cdot 6 \%$ ). Twenty-eight percent of embryos developed into morulae and blastocyst compared with $8.2 \%$ in the oviductal monolayer system (Table 5). The peak of embryo development into blastocysts occurred 7 days after insemination when embryos were co-cultured with oviductal monolayer system and 6 days after culture in ligated rabbit oviduct respectively (Fig. 4).

Table 5. Comparison of early development in buffalo ova after incubation in ligated rabbit oviduct and buffalo oviduct cell monolayer

\begin{tabular}{lccc}
\hline & $\begin{array}{c}\text { Total } \\
\text { oocytes }\end{array}$ & $\begin{array}{c}\text { Cleavage } \\
(\%)\end{array}$ & $\begin{array}{c}\text { Morula: } \\
\text { blastocyst (\%) }\end{array}$ \\
\hline Rabbit oviduct & 313 & $121(38 \cdot 6)$ & $34(28 \cdot 0)$ \\
Oviduct cell monolayer & 384 & $45(11 \cdot 0)$ & $4(8 \cdot 2)$ \\
\hline
\end{tabular}

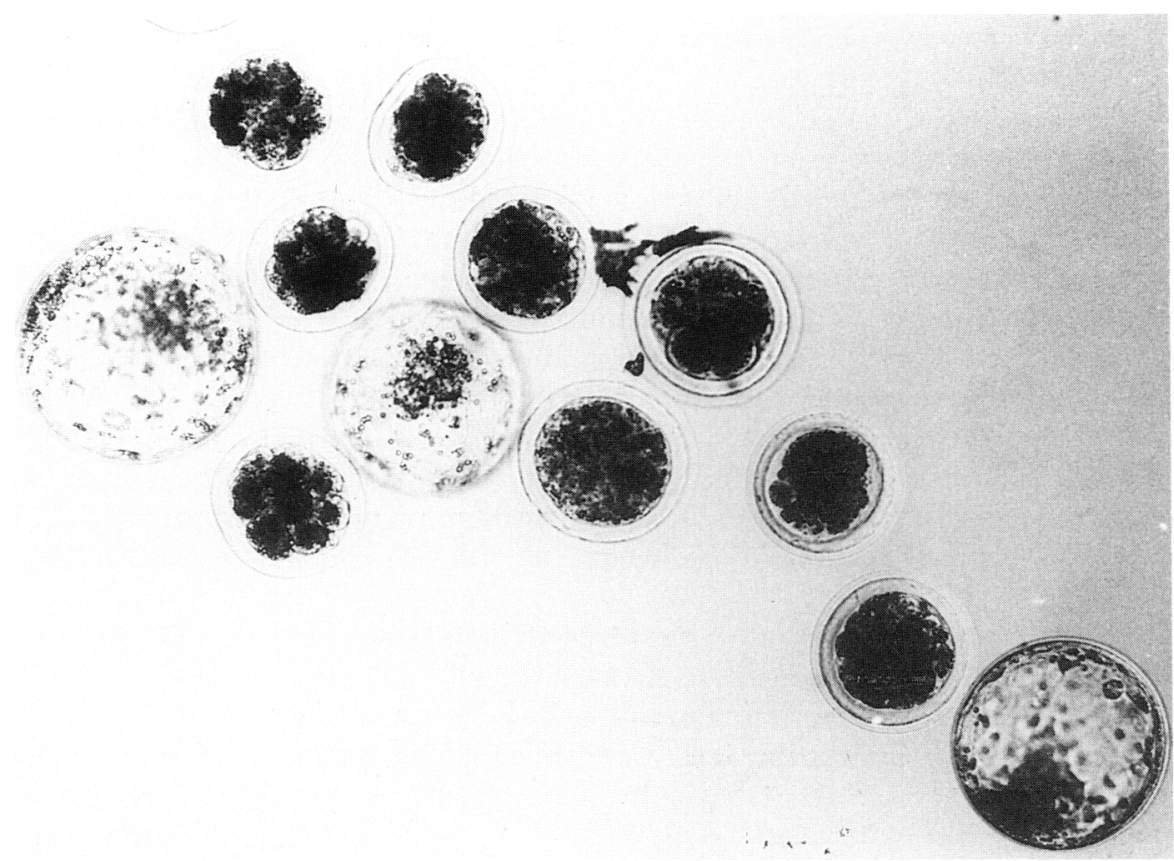

Fig. 4. Buffalo ovum cultured in ligated rabbit oviduct for 5 days after in vitro fertilization: expanded blastocysts and morulae are visible $(\times 85)$.

\section{Discussion}

The present study was undertaken to develop an efficient method for IVF in buffaloes. Overall yield of total and usable oocytes per ovary was low in buffalo compared with cattle, in which the number of oocytes per ovary is up to 10 (Gordon $\& \mathrm{Lu}, 1990$ ). The low recovery of oocytes per ovary in buffalo can be attributed to the low average number of primordial follicles in the ovaries (12 636 
in cycling buffalo and 10132 in non-cycling buffalo) (Danell, 1987). Samad and Nasseri (1979) reported that the Surti breed of buffalo has 12000 primordial follicles and the Nilli Ravi breed has 19000 primordial follicles in contrast to one hundred thousand in cattle ovary.

The average frequency of atresia for all the buffaloes was reported to be as high as $70.6 \%$. However, more information is required on the incidence and extent of follicular atresia in relation to follicular size and the reproductive status of the buffalo that are being used as the source of ovaries.

Eight protocols for oocyte maturation were investigated. When selected oocytes were cultured in the presence of $20 \% \mathrm{BES}$ and gonadotrophins, a significant increase in maturation rate was observed compared with that obtained with $20 \%$ BES alone. The effect of adding FSH, LH, oestradiol and progesterone during maturation of bovine oocytes have been studied by many workers (Hensleigh \& Hunter, 1985; Stubbing et al., 1988). Our study on buffalo IVM demonstrates that addition of hormones resulted in a significant increase in maturation rate. Present data agree with the report of Fukashima and Fukui (1985) and Younis et al. (1989), who found that the maturation rate of bovine oocytes was significantly increased by the addition of $\mathrm{LH}$ or a combination of $\mathrm{LH}$, FSH and oestradiol compared with controls with no added hormone. However, it was observed that $5 \mu \mathrm{g} \mathrm{LH} \mathrm{m} l^{-1}$ in Ham's F-10 medium supplemented with $20 \%$ BES significantly enhanced the rate of maturation compared with medium lacking $\mathrm{LH}$, and the addition of FSH and oestradiol failed to synergize with LH. In contrast, addition of LH in TCM-199 supplemented with $20 \%$ BES failed to enhance the rate of maturation but addition of FSH and oestradiol significantly enhanced the rate of maturation.

Although various procedures for capacitating bull spermatozoa have been used for IVF, the most effective to date is the method of Parrish et al. (1984), who demonstrated that heparin could increase the frequency of IVF. However, this was not confirmed in buffaloes. Fertilization rate was very low $(19 \cdot 6 \%)$ when frozen-thawed spermatozoa treated with $10 \mu \mathrm{g}$ heparin $\mathrm{ml}^{-1}$ in HepesTalp medium were used. Similar results were observed in IVF in buffalo by Singh et al. (1989), although maturation rate was more than $75 \%$. There was no improvement in fertilization rate when frozen-thawed spermatozoa treated with penicillamine, hypotaurine and adrenaline or in combination with heparin in Hepes-Talp medium were used.

Fertilization rate was improved when preparation of frozen-thawed spermatozoa was carried out in BO medium and treated with 5 mol caffeine $1^{-1}$ and $10 \mu \mathrm{g}$ heparin. Fertilization rate was further improved when fresh ejaculated semen was treated with caffeine and heparin in BO medium $(50 \%)$. It has been observed that the IVF rate of bovine oocytes increased significantly when caffeine was added to heparin in the fertilization medium, suggesting a synergistic effect between these chemicals in stimulating IVF of bovine oocytes (Ohgoda et al., 1987; Niwa \& Ohgoda, 1988; Park et al., 1989).

However overall fertilization rate with frozen-thawed semen in buffalo IVF is quite low compared with that reported for bovine IVF. It may be due to leakage of various enzymes like acrosin and hyaluronidase on preservation. Enzyme release has generally been recognized as cellular injury, whereby membranes become inactivated or destroyed resulting in loss of cellular material (Ganguli, 1979). There is evidence from electron microscopic studies that the plasma membrane of buffalo spermatozoa is quite fragile particularly in the acrosome region (Anand, 1979). Buffalo spermatozoa have low survival rate and thus lower fertilizing ability when semen is either refrigerated or deep frozen (Rawat, 1979).

Preservation of buffalo semen is a long-standing problem. Various media have been used for storage and preservation of buffalo semen (Matharoo \& Singh, 1980; Nath et al., 1991). The motility diminished in all the media used with increase in number of hours of preservation (Vyawahare et al., 1989; Sidhu \& Guraya, 1979). Meur and Dhoble (1988) demonstrated cryogenic changes in acrosomal proteins of buffalo spermatozoa. They found that total sulfhydryl group decreased owing to freezing and to irreversible damage to acrosome proteins during cryopreservation. 
We could improve the fertilization rate when preparation of frozen-thawed spermatozoa was carried out in BO medium treated with caffeine and heparin. Increased stimulation could result from easy access of caffeine in the membrane-damaged spermatozoa. Motility of buffalo spermatozoa after freezing was reported to be increased by 25 to $100 \%$ on addition of $6 \mathrm{mmol}$ caffeine $1^{-1}$ (Gehlaut \& Srivastava, 1987).

A high fertilization rate was observed when fresh ejaculated semen was used, whereas fertilization rate was reduced significantly when diluted semen, or frozen semen was used. These results confirm the observation that preservation and freezing of buffalo semen significantly reduced fertilization capacity.

Uterine, oviductal and follicular fluid contains glycosaminoglycans (Lee \& Ax, 1984; Lee et al., 1986; Ax \& Bellin, 1988). Heparin was the glycosaminoglycan that was considered to be most potent and most consistent in stimulating the acrosome reaction and fertilization in vitro in cattle, but heparin was not effective in capacitating buffalo spermatozoa. However, Sidhu et al. (1990) demonstrated a $39 \cdot 8 \%$ acrosome reaction of fresh ejaculated buffalo spermatozoa when treated with $2 \%$ deoxified uterine fluid. It is necessary to confirm that this results from the presence of glycosaminoglycans in the uterine fluid or the presence of some other proteins. Detailed studies will have to be carried out on the dose-dependent effect of heparin on frozen-thawed buffalo spermatozoa, isolation of glycosaminoglycans in the uterine fluid or oviductal fluid and effect of individual bull variation on buffalo IVF.

In our experiment fresh ejaculated semen was more effective when treated with caffeine and heparin in BO medium than frozen-thawed semen. A higher cleavage rate was observed when spermatozoa were treated with caffeine and heparin in BO medium than in untreated spermatozoa.

We compared culture systems for development of early buffalo embryos. Embryos were cocultured either on buffalo oviductal cell monolayer or ligated rabbit oviduct. Developmental rate was significantly lower on oviductal cell monolayer $(8.2 \%)$ than when co-cultured in ligated rabbit oviduct ( $28 \%$ ). Most of the embryos cultured on oviductal cell monolayer did not develop beyond the four-cell stage. Bovine embryos are particularly sensitive to culture condition at the eight- to 16-cell stage (Eyestone \& First, 1989) and pigs, at the four-cell stage (Mattioli et al., 1989), since embryos block at this point in a variety of media. However, recent co-culture of bovine embryos on monolayer of oviductal cells improved viability and development beyond the 8-16-cell stage (Eyestone \& First, 1989) and was efficient and cheap. However, similar results were not observed in buffalo. Lu $e t$ al., (1989) derived as many as $60 \%$ of embryos using sheep oviduct. However, for the large-scale production of buffalo embryos the use of rabbits or sheep as an intermediate host would be unsuitable. More work is needed for the development of efficient in vitro culture system for buffalo embryos.

There are many limitations in buffalo IVM, IVF, in vitro culture, in terms of lower yield of usable oocyte, high atresia, low fertilization rate, seasonal effect on follicular recruitment and quality of oocytes, seasonal effect of quality of semen, and the quality of buffalo that are slaughtered, which will have to be taken into consideration while performing IVF in buffalo.

This work was supported by the Department of Biotechnology under the Science and Technology mission project on cattle herd improvement through embryo transfer technology. We thank RadheShyam and Inderjeet for their technical help, Ramesh for typing the manuscript, S. Chandran for critical reading of the manuscript, H. L. Abhi for generous supply of fresh ejaculated semen of buffalo and W. H. Eyestone and A. V. D. Schan for technical suggestions. Hormones were donated by the National Institute of Diabetes and Digestive and Kidney Diseases, NIH, USA.

\section{References}

Anand, S.R. (1979) Buffalo sperm metabolism: an assessment of motility, live sperm counts and leakage of acrosomal enzymes from buffalo spermatozoa during dilution and preservation. In Proceedings of $\mathrm{FAO} /$ SIDA Seminar on Buffalo Reproduction and Artificial
Insemination, pp. 284-291. FAO, United Nations, Rome.

Ax, R.L. \& Bellin, M.E. (1988) Glycosaminoglycans and follicular development. Journal of Animal Sciences $\mathbf{6 6}$ (Supplement 2), 32-49. 
Bracket, B.G. \& Oliphant, G. (1975) Capacitation of rabbit spermatozoa in vitro. Biology of Reproduction 12, 260-274.

Brackett, B.G., Bousquet, D., Boice, M.L., Donawick, W.J., Evans, J.F. \& Dressel, M.A. (1982) Normal development following in vitro fertilization in the cow. Biology of Reproduction 27, 147-158.

Danell, B. (1987) Oestrous Behaviour, Ovarian Morphology and Cyclical Variation in Follicular System and Endocrine Pattern in Water Buffalo Heifers, pp. 54 94. Sveriges Lantbruksuniversitet Uppsala.

Eyestone, W.H. \& First, N.L. (1989) Co-culture of early cattle embryos to the blastocyst stage with oviductal tissue or in conditioned medium. Journal of Reproduction and Fertility 85, 715-720.

Fukushima, M. \& Fukui, Y. (1985) Effect of gonadotropins and steroids on the subsequent fertilizability of extrafollicular bovine oocyte matured in vitro. Animal Reproduction Science 9, 323-332.

Ganguli, N.C. (1979) Biochemistry of semen processing. Proceedings of Buffalo Reproduction and Artificial Insemination FAO/SIDA, pp. 292-303. FAO, United Nations, Rome.

Gehlaut, B.S. \& Srivastava, R.K. (1987) Effect of caffeine citrate on post-thawed motility of buffalo bull spermatozoa. Theriogenology 28, 767-772.

Gordon, I. \& Lu, K.H. (1990) Production of embryos in vitro and its impact on livestock production. Theriogenology 33, 77-87.

Hensleigh, H.C. \& Hunter, A.G. (1985) In vitro maturation of bovine cumulus enclosed primary oocytes and their subsequent in vitro fertilization and cleavage. Journal of Dairy Sciences 68, 1456-1462.

Karaivanov, C., Kacheva, D., Petrov, M., Vlahov, K. \& Sapundjiev, E. (1990) Superovulatory response of river buffalo (Bubalus bubalis) Theriogenology 33, 453-464.

Kurup, M.P.G. (1988) Present status of embryo transfer in buffaloes and future expectations. Proceedings of II World Buffalo Congress, II, pp. 587-590. Indian Council of Agricultural Research, New Delhi.

Lee, C.N. \& Ax, R.L. (1984) Concentration and composition of glycosaminoglycans in the female bovine reproductive tract. Journal of Dairy Sciences 67, 2006-2009.

Lee, C.N., Clayton, M.K., Bushmeyor, S.M., First, N.L. \& Ax, R.L. (1986) Glycosaminoglycans in ewe reproductive tracts and their influence on acrosome reaction in bovine spermatozoa in vitro. Journal of Animal Science 63, 861-867.

Lu, K.H., Gordon, I., Gallagher, M. \& McGovern, H. (1989) Pregnancy established in cattle by transfer of embryos derived from IVF oocytes matured in vitro. Veterinary Record 121, 259-260.

Madan, M.L. (1990) Factor limiting superovulation response in embryo transfer programme among buffaloes. Theriogenology 33, 280 (Abstract).

Matharoo, J.S. \& Singh, Mehar (1980) Revivability of buffalo spermatozoa after deep freezing the semen using various extender. Zentralblatt Fur Veterinarmedizin A.27, 385 .

Mattioli, M., Bacci, M.L., Galeati, G. \& Seren, E. (1989) Developmental competence of pig oocytes matured and fertilized in vitro. Theriogenology 31, 1201-1207.
Meur, S.K. \& Dhoble, R.L. (1988) Cryogenic changes in acrosomal proteins of buffalo spermatozoa. Proceedings of the II World Buffalo Congress I. 55 (Abstract). Indian Council of Agricultural Research, New Delhi.

Mishra, A.K., Joshi, B.V., Kashiraj, R., Sivaiah, S. \& Rangareddi, N.S. (1991) Improved superovulatory regimen for buffalo (Bubalus bubalis). Theriogenology 35, 245 (Abstract).

Mujumdar, A.C., Katiyar, P.K., Raminder Singh, V.K. Taneja \& Bhat, P.N. (1988) Maturation of slaughterhouse ovarian follicular oocytes of buffalo in culture and subsequent in vitro fertilization. Proceedings of the II World Buffalo Congress I 54, (Abstract).

Nath, R., Tripathi, S.S., Saxena, V.B. \& Tripathi, R.P. (1991) Tris diluent and freezability of buffalo semen. Indian Veterinary Journal 68, 135-138.

Niwa, K. \& Ohgoda, O. (1988) Synergistic effect of caffeine and heparin on in-vitro fertilization of cattle oocytes matured in culture. Theriogenology 30, 733741

Ohgoda, O., Niwa, K., Yuhara, M., Takahashi, S. \& Kanoya, K. (1987) Variations in penetration rates in vitro of bovine follicular oocytes do not reflect conception rates after artificial insemination using frozen semen from different bulls. Theriogenology 29, 1375-1381.

Park, C.K., Ohgoda, O. \& Niwa, K. (1989) Penetration of bovine follicular oocytes by frozen-thawed spermatozoa in the presence of caffeine and heparin. Journal of Reproduction and Fertility 86, 577-582.

Parrish, J.J., Susko-Parrish, J.L. \& First, N.L. (1984) Effect of swim up separation and heparin treatment of frozen-thawed spermatozoa on in vitro fertilization of bovine oocytes. Biology of Reproduction 30, 112 (Abstract).

Parrish, J.J., Susko-Parrish, J.L., Leibfried-Rutledge, M.L., Crister, E.S., Eyestone, W.H. \& First, N.L. (1986) Bovine in vitro fertilization with frozenthawed semen. Theriogenology 25, 591-600.

Rawat, J.S. (1979) Physicochemical factors in buffalo spermatozoal activity. Proceedings of Buffalo Reproduction and Artificial Insemination FAO/SIDA. pp. 284-291.

Samad, H.A. \& Nasseri, A.A. (1979) A quantitative study of primordial follicles in buffalo heifer ovaries. Compendium 13th FAO/SIDA International Course on Animal Reproduction, Uppsala, Sweden.

Sidhu, K.S. \& Guraya, S.S. (1979) Morphological biochemical and physiological studies on the preservation of buffalo (Bubalus bubalis) spermatozoa in different modified dilutors: effect of chloroquine diphosphate. Annales de Biologie Animale Biochemistry and Biophysics 19, 4554.

Sidhu, K.S., Bassi, A., Singh, N. \& Guraya, S.S. (1990) Effect of uterine fluid on in vitro acrosome reaction of buffalo (Bubalus bubalis) spermatozoa. Theriogenology 33, 569-576.

Singh, G., Totey, S.M. \& Talwar, G.P. (1989) In vitro fertilization of buffalo oocytes matured in vitro. Theriogenology 31, 255 (Abstract).

Stubbing, R.B., Betteridge, K.J. \& Asrur, P.K. (1988) Investigations of culture requirements for bovine oocyte maturation in vitro. Theriogenology 29, 313 (Abstract).

Takahashi, Y., Nihayah, M., Hishinuma, M., Jainudeen, M.R., Mazni, O.A., Mori, Y. \& Kanagawa, H. (1989) 
Preliminary study of buffalo sperm penetration into zona free hamster eggs after treatment with calcium ionophore A23187. Japanese Journal of Veterinary Research 37, 161-166.

Totey, S.M., Singh, G., Taneja, M. \& Talwar, G.P. (1991) In vitro maturation and fertilization of follicular oocytes from buffalo. Theriogenology 35, 284.

Vlahov, K., Karaivanov, C., Petrov, M., Kacheva, D., Alexiev, A., Polihronov, O. \& Danev, A. (1985) Studies on superovulation and embryo transfer in water buffaloes. Proceedings of the First World Buffalo Congress. III, pp. 510-515.

Vyawahare, R., Chauhan, R.A.S., Nema, S.P. \& Porwal, M.L. (1989) Studies on seminal attributes, enzyme leakage and preservability of buffalo semen. Indian Veterinary Journal 66, 1128-1132.

Younis, A.I., Brackett, B.G. \& Fayrer-Hosken, R.A. (1989) Influence of serum and hormones on bovine oocyte maturation and fertilization in vitro. Gamete Research 23, 189-201.

Received 9 May 1991 